\title{
Online-BSEE (Online Bachelor of Science in Electrical Engineering): A Multi- University Collaboration Project in Partnership with Open SUNY
}

Prof. Wendy K Tang, Stony Brook University

Wendy Tang is an Associate Professor at the Department of Electrical and Computer Engineering in Stony Brook University. She received her B.S., M.S. and Ph. D in Electrical Engineering from the University of Rochester. Her current research interests are in Wireless Sensor Networks, Communication Networks and Graph Theory Applications. She and her colleagues are the recipients of two best paper awards in 1997 and 1998. She is also an accomplished educator. Her dedication in promoting women in engineering was recognized by an IEEE Region 1 Award in 1998, an IEEE Regional Activity Board Achievement Award also in 1998 and an IEEE Third Millennium Medal Award in 2000. In 2004, together with Dr. Serge Luryi, Dr. Tang initiated a project that promotes entrepreneurship in engineering education in collaboration with three other higher education institutions on Long Island. For their pioneering contributions, the IEEE Long Island Section awarded Dr. Luryi and Dr. Tang, the Athanasios Papoulis Education Award in 2006. Dr. Tang is currently the Associate Chair for the Electrical and Computer Engineering Department. She also serves as the Faculty Director for the Honors College and the Program Director for the Bachelor of Science in Electrical Engineering Online program.

\section{Prof. Pao-Lo Liu, University at Buffalo, SUNY}

Dr. Pao-Lo Liu graduate from Harvard University with Ph. D. in 1979. He was with Bell Telephone Laboratories and Bell Communications Research from 1979 to 1984 . He joined University at Buffalo, SUNY in 1984. Since 1987, he has been Professor in Electrical Engineering. Dr. Liu made contributions in laser-induced phase transition, picosecond semiconductor laser sources, high speed electrooptic devices, photon statistics, photonic CAD tools, and statistical key exchange for secure communications. He has been involved in the Online Bachelor of Science in Electrical Engineering Program since its inception. He developed the electronics laboratory I and II to offer hands-on experiences to online students. Dr. Liu is a member of Optical Society of America.

\section{Dr. Charles R. Westgate Sr. P.E., Binghamton University}

Charles Westgate is a Research Professor at Binghamton University and a former Dean of the Engineering School at Binghamton. He has been deeply involved in online course instruction at Johns Hopkins, Binghamton, and Stony Brook. He conducts research in semiconductor devices and materials.

\section{Ms. Kim A. Scalzo, State University of New York, HQ}

Kim Scalzo is Director of the SUNY Center for Professional Development (CPD). The SUNY CPD provides professional development and training opportunities for faculty and staff across SUNY's 64campus system. CPD programs and services are targeted toward campus administration and leadership, faculty and instructional support staff, and IT staff. As Director, Kim provides overall leadership for the center, including strategic planning, new program development, campus relationship management, and partnership development with training vendors. At SUNY Kim is also leading the Campus Partnerships for the implementation of Open SUNY in support of SUNY's Strategic Plan, The Power of SUNY.

Prior to joining the SUNY in 2009, Kim spent 18 years at Rensselaer Polytechnic Institute, her last position as Director of Academic Outreach Programs with overall responsibility for Rensselaer's Distance Learning, Continuing Education, summer, and Outreach programs. Kim has also served as a reviewer for the New York State Education Department Office of Higher Education for several Institutional Capability Reviews for distance learning programs. Over the past six years she has participated in an EU-US collaboration to develop international quality standards for continuing education and is leading the Open SUNY Institutional Readiness program to implement quality standards for continuing education and distance learning organizations based on the Online Consortium Quality Scorecard. She is also a co-creator of the Bray-Scalzo Partnership Model for creating and sustaining successful partnerships in higher education. 
Kim currently serves as President for the International Association of Continuing Engineering Education (IACEE) Council and is the Past-Chair of the Executive Board for the Continuing Professional Development Division of the American Society for Engineering Education (ASEE-CPD). Additionally, she has served as a member of the National University Telecommunications Network (NUTN) Advisory Board and is currently a member of the SUNY Plattsburgh Alumni Association Board of Directors, the SUNY Prrovost's Open SUNY Advisory Council (POSAC), the Faculty Council on Teaching and Technology (FACT2), the SUNY Council on Assessment (SCoA), the SUNY Shared Services Steering Committee, the SUNY Language Consortium, the SUNY Alliance for Strategic Technologies, and the Executive Board for the SUNY Information Technology Exchange Center (ITEC). Kim received her bachelor's degree in Computer Science from SUNY Plattsburgh and master's degree in Education in College Student Personnel from the College of Saint Rose. 


\title{
Online-BSEE (Online Bachelor of Science in Electrical Engineering): A Multi-University Collaboration Project
}

\begin{abstract}
The Online Bachelor of Science in Electrical Engineering is a collaborative effort among three SUNY University Centers Stony Brook, Buffalo, and Binghamton. The program delivers the entire electrical engineering curriculum, including the laboratory component asynchronously at the bachelor level to students online; thus realizing the Learning Anywhere Anytime vision. Students take the basic mathematics and science courses and general education curriculum elsewhere (online or at local institutions). It is one of the first such programs nationwide in which faculty from multiple universities join forces to serve a unique online student body distinct from the traditional on-campus students. Thus far, our student body consists of mostly working professionals seeking career advancement. Some are electrical or electronic technicians seeking the degree for promotion. Some are intellectual property lawyers in different engineering disciplines seeking to expand their practice to include electrical engineering. There are yet others seeking completion of their bachelor degrees that were interrupted by various life scenarios. In this paper, we discuss the triumphs and challenges of the program and outline how our collaboration across three universities and other partnership further enables us to leverage the resources of a large public education system to make a difference and to serve a student body that is otherwise unable to pursue higher education in electrical engineering. We will also share our comprehensive model of program supports and how we plan to measure the usage, effectiveness, and long term impact of those supports over time.
\end{abstract}

\section{Introduction}

The Electrical and Computer Engineering Department at Stony Brook University seeks to educate engineers who will possess basic concepts, proficiency in using modern tools, and necessary skills to maintain the technological and economic competitiveness of United States. Our faculty is totally committed to this vision and understands that the realization of this goal requires an expansion of the traditional pipeline of STEM students [1]. In 2006, when Sloan Foundation offered a grant to experiment with online electrical engineering courses, our faculty rose up to the challenge and embraced the opportunity for innovations in online education.

Today, the Bachelor of Science in Electrical Engineering (BSEE) program provides a unique opportunity for mature and motivated individuals to pursue a bachelor's degree in electrical engineering by offering the entire electrical engineering curriculum, including electronic laboratory courses, online and asynchronously - thus realizing Sloan Foundation's vision of learning anywhere, anytime [2,3]. Furthermore, the degree program is supported by faculty from three University Centers in a public university system- essentially allowing us to join forces to serve a student body that otherwise is unable to pursue higher education in electrical engineering.

From the onset, we consciously opt for a gradual and prudent approach to build the program "from scratch" - totally separated from our on-campus ABET accredited program, Bachelor of Engineering in Electrical Engineering (BEEE). Every course in the program with a designator "EEO" goes through the curriculum approval process. Students in the on-campus program (BEEE) 
are not allowed to take EEO courses which are restricted to "major only". The entire degree program went through regional accreditation - a process that took five years to complete. In May 2011, we received the State accreditation and two students graduated from the program in May 2014.

As a result of this prudent approach and the strict admission requirement to ensure that students are qualified with strong Calculus and Physics background, our classes always have a small enrollment with the largest class size so far being eleven students. The small enrollment enables the faculty to develop insight in this new format of delivery for course content and devote attention to individual students which is difficult to accomplish in a large public university. Thus far, our experience indicates that the program is most suitable for mature and motivated individuals who seek career advancement and personal growth. These individuals often can benefit from the more reflective online learning environment in which they can take time to contemplate and relate course content to their own professional experiences. The program, however, is not suitable for young students who just graduated from high school and need more real-time interactions with instructors and social support from peers.

In terms of technical courses, the program consists of sixteen core courses and four technical electives from a list of nine technical electives. We are continuing to enhance the course offering by adding more core courses and technical electives. For the up-to-date curriculum, please visit the following webpage: http://www.stonybrook.edu/eeonline/. We emphasize that the entire electrical engineering curriculum including laboratory courses are offered completely online and asynchronously. Students can complete these electrical engineering courses without the need to visit the campus. A more detailed description of how the laboratory courses are offered online is included in [paper published in the Journal of Educational Technology 2014].

In this paper, we present the triumphs and challenges in Section 2. Section 3 describes the collaboration and program identify. A comprehensive model of program support is outlined in Section 4. Section 5 presents the summary and conclusions.

\section{Triumphs and Challenges}

The most prevailing triumph of the program is its ability to deliver the entire electrical engineering curriculum including the laboratory courses online and asynchronously. This mode of delivery allows us to reach a student body that is otherwise unable to pursue a bachelor degree in electrical engineering. Our success for online laboratory is due to a pioneering and innovative approach for electronic instrumentation initiated by our faculty. A more detailed description of the laboratory component is provided in our journal paper [Journal of Education Technology]. Other online electronic laboratory resources can be found in [4-11]. This mode of delivery allows us to reach a student body that is otherwise unable to pursue a bachelor degree in electrical engineering. 
Since the inauguration of the degree program in May 2011, we have developed insights and gradually established a unique identity for the program. First and foremost, the student body in our online program is drastically different from that of the standard on-campus students who are young adults typically in their late teens, or early twenties and just graduated from high school. In terms of age, the online students tend to be - in their thirties, forties, or even older. Second, in terms of education, the online students have attended college or a number of colleges and universities many years prior to applying to our online program. They either have completed an Associate Degree, a bachelor degree typically non-engineering, or just taken a number of courses. Many of these students also dropped out of college many years ago, due to family or financial reasons, or due to mediocre academic performance. In other words, these online students are usually mature individuals. They enrolled in the program with a specific goal of completing their college degree or extending their expertise for career advancement. Unlike the on-campus students who have just graduated from high school, these individuals often have rich life experiences and are not looking for the social aspect of the college experience. At the time of the application to the online program, practically all of them hold jobs and are more mature and focused students. They either seek the bachelor degree for advancement in their current place of work or to expand their expertise. For example, we have several patent attorneys who need their EE diploma to widen the range of their expertise.

The different demographics of the online students pursuing the Bachelor of Science in Electrical Engineering have a major impact on how they pursue the degree compared to on-campus students. Being older and typically married, they need to be able to complete their degrees with flexible schedules and are subjected to delays in their progress towards the degree as a result of being sick, losing their jobs, having marital problems, or being transferred by their companies to different locations across the country or around the world. Because of these factors, it is common for them to interrupt their academic progress for a semester or two, and pick it up later (or even drop it). In addition, these students can only take one or two courses each semester. However, for those who persevere, they are usually more motivated and often possess a genuine interest to learn the engineering concepts. Furthermore, the online learning environment is conducive to a more reflective mode of learning in which students take time to reflect and relate course materials to their own professional and life experience $[12,13]$. Many of our colleagues with long careers in engineering education feel that these students are a joy to teach and some are their best students.

Another triumphs of the program is the use of online content as resources for on-campus face-toface offering. On-campus students are given access to some of the online content involving substantial mathematical concepts. In these online content, applets and visualization tools available on the web are extensively used. Students can control most of the applets to answer "what-if?" questions. The applets can also be used to support complex calculations and geometrical representations, particularly in electromagnetics and signal processing, to reduce errors and allow students to focus on understanding the materials. The use of these online resources allows the instructor to dedicate the face-to-face lectures with more in-depth discussions. Such use of "flipped lectures" creates a win-win combination for both online and on-campus education.

For challenges, we encounter two issues: (1) how to engage students in multidisciplinary team projects; and (2) how to ensure student authentication. 
As an engineering program, one of our expected student outcomes is an ability to function on multidisciplinary teams. However, perhaps partly due to the small size of the program, most of our capstone design projects are done individually. To enhance students' team experience, we are currently working on two approaches: to have students working on similar capstone design projects provide feedback to each other and to have online capstone design students team up with oncampus students. For example, online students working in the area of telecommunications form one group, students in the electronics area form another group. These groups of students share their capstone design projects and provide support and feedback to each other via Blackboard discussion group and E-Portfolios. We also have one online student develop the software coding for a team of on-campus students that work on the hardware aspect of the project. In these cases, our goal is to provide the same real-life experience of industry in which coworkers solicit and give inputs and feedbacks to various engineering projects.

Student authentication is a common challenge to all online programs. There are various software and tools for plagiarism detection. However, since most of our courses are mathematical and technical oriented, these tools are not applicable. Instead, we encourage students to use proctoring center as those listed in the National College Testing Association (http://www.nctatesting.org/cctc/find.php). There are also various online proctoring facilities such as proctorU (proctoru.com), Examity (examity.com), Proctor Free (proctorfree.com), etc. They provide online proctors to monitor students doing the examinations at home via a standard webcam on the computer. Proctor is required for written examinations. Only highly individualized projects can be exempt from having proctors.

\section{Multi-University Collaboration and Program Identity}

One unique aspect of the program is that it is supported by faculty of three university centers under a large public university system with multiple campuses.

The collaboration was initiated with a Sloan Foundation grant to offer non-matriculated electrical engineering courses online in 2006, almost five years before the inauguration of the degree granting program in May 2011. For the past eight years, without interruption, two faculty from Buffalo and two faculty members from Binghamton continue to offer electrical engineering courses online as part of the collaboration. In fact, it is this collaboration that allows us to share faculty resources to offer the full spectrum of courses in the program as none of the three university centers has the faculty resources to offer the entire electrical engineering curriculum online.

Over the past eight years, the following faculty members, one from each of the three campuses, have been involved with the project and they naturally became the leaders and members of the "Executive Committee" of the program. The committee initiates many changes which are subsequently discussed and voted in faculty meetings. The executive committee has bi-weekly conference phone calls during academic years to discuss various issues and also acts as a point-ofcontact for faculty in the respective campus. The members of the Executive Committees are: Wendy Tang at Stony Brook, Pao Lo Liu at Buffalo, and Charles Westgate at Binghamton, coauthors of this paper. Today, the trio remain leaders of the program to facilitate communications 
among faculty in the three campuses. The collaboration has been very rewarding as each one has his/her own unique experience and strength. Together they form a strong faculty core.

Given the departments of each of the University Center already has an ABET accredited program in Electrical Engineering on campus, at the inception of the online program, we modeled the online version based on the leading campus' face-to-face program including its program educational objectives (PEOs), student outcomes, and curriculum.

A question naturally arises. What would be the different identities of the two programs? This question was not treated lightly, but gave rise to a great deal of soul-searching and discussions among faculty. In the onset of the project, there was a vision among some of faculty that online education would eventually play a pivotal role in education. Hence, it was deemed important that we should participate in online education at the early stage and gain insight into the delivery format to be the pioneer of engineering education. There was, however, a valid concern that our oncampus ABET-accredited program and on-campus students should not be negatively impacted by the online program. Hence, we opt for a gradual and prudent approach to build the program "from scratch" - building each course separately and courses in the online program are for the major only, hence barring on-campus students from taking the online courses. On hind-sight, this gradual approach has provided a safeguard for us to develop insight into offering online electrical engineering courses. Since the beginning of the program in May 2011, we always have small classes - with the largest class size being 11 students. Such small class setting allows the faculty to pay attention to individual students and gradually improve the content and delivery mode through continuous improvement via outcome based assessment.

In terms of establishing a unique identity for the online program, we added an outcome "l" - ability to communicate and/or collaborate online as a natural outcome of the delivery mode of the program. In Fall 2013, through insight developed with interactions with the online students, we gained a very clear vision that the BSEE program is serving a mature student body with a rich life experience. Through our multi-university collaboration, we are essentially serving a distinct population that would otherwise be unable to pursue a bachelor degree in electrical engineering. This insight has led to a newly revised set of PEOs that provides a more distinct identity of the program. In Spring 2014, the Executive Committee members drafted a simplified version of PEOs:

PEO 1: Our graduates should excel in engineering positions and career advancements in industry and other organizations that emphasize design and implementation of engineering systems and devices.

PEO2: Our graduates should excel in professional developments including advanced degrees in engineering and related discipline.

The program has its first two graduates in May 2014. We have gone through an ABET accreditation visit in Fall 2014 and are awaiting the results of the visit.

In the academic year 2015-16, we plan to solicit inputs of this new set of PEOs from our constituencies: employers, alumni, students and faculty. Typically, in the first 3-year period of 
the ABET cycle, we solicit inputs from our constituencies about the adequacy of the PEOs to serve their needs; necessary changes are made, in any, at the end of the first 3-year period. In the second 3-year period, we focus on assessing how the PEOs are met by our graduates.

\section{A Comprehensive Model of Program Support}

Another recent development of the program is that in January 2014, the BSEE program is in partnership with the State University system to put together resources for online degree programs in different campuses via the Open SUNY partnership.

Open SUNY is a SUNY-wide collaboration allowing students to seamlessly access online courses and degrees programs across all 64 SUNY campuses. It is not a new degree program or a new school. Instead, the partnership provides the BSEE program with a comprehensive model of program support from faculty to students. As part of the partnership, students in the online program are provided with support services such as tutoring, 24/7 help desk technical support for the Blackboard Learning Management system, a single-point of contact for questions on various issues, an early alert system, etc. More details on Open SUNY can be found in [14].

Furthermore, faculty teaching online are also supported with training, multi-media specialists and instructional designers for course development or enhancement. Currently, three of the courses developed for the program are undergoing revision with the help of instructional designers from Open SUNY. Our plan is to continue to revise courses each to maintain high quality.

\section{Summary and Conclusions}

In this paper, we describe a collaborative effort among three university centers in a public university system to launch a Bachelor of Science Degree program in Electrical Engineering completely online and delivered asynchronously. Thus realizing the learning anywhere anytime vision. The collaborative effort allows the university centers to share resources and faculty expertise which a single institution cannot support. Our goal is to join forces to make a difference in serving a student population that otherwise would be denied higher education in electrical engineering. Indeed, the demography of our student body indicates that most are adult learners, often are working professionals seeking career advancement while managing family or personal obligations.

Our experiences thus far are very rewarding. Some of our colleagues with long careers in engineering education for more than 20 years mentioned that they had seen the best students in these online courses. Feedback from students is also very positive with most enjoying the vigor and flexible schedule of courses.

However, there continue to be challenges in online education. Among which are the common challenges such as student authentication/verification, student engagement, student/faculty interaction, etc. Educators are working to tackle these challenges. For example, to verify a student's identify, some programs use testing centers. Others use an individual's rate of typing as a personal identifier. Even finger prints are considered. Various collaboration software and 
technology are introduced by commercial companies designed to promote online collaboration and interaction. Some examples include Adobe Connect, Collaborate, Voicethread, etc.

In summary, our journey in establishing the online Bachelor of Science in Electrical Engineering program is a long and rewarding one. Through the collaborative effort, we attest that online learning can facilitate and strengthen cross-disciplinary communities of research and education via online collaboration. It facilitates the "learning to learn" paradigm where the teacher also becomes the learner.

In conclusions, through our experience, we believe that the online learning paradigm is conducive to the 21 st-centry education where creativity, critical thinking, communication and collaboration are encouraged.

\section{References}

1. S. Patrick, "E-Learning: A Federal Perspective", U.S. Department of Education, (www.nutn.org/susan_patrick.pdf).

2. J. Bourne, D. Harris, F. Mayadas, "Online Engineering Education: Learning Anywhere, Anytime”, Journal of Asynchronous Learning Network, 9(1), pp. 15-41 (2005).

3. A. F. Mayadas, "What is ALN?" (http://www.aln.org.alnweb.aln.htm).

4. L. Palma, R. F. Morrison, P. N. Enjeti, J W. Howze "'Use of Web-Based Materials to Teach Electric Circuit Theory,, IEEE Transactions on Education, 48 (4) November 2006.

5. W. G. Hurley. C. K. Lee, "Development, Implementation, and Assessment of a Web-Based Power Electronics Laboratory”, IEEE Transactions on Education, 48 (4), November 2005.

6. Lyle D. Feisel and Albert J. Rosa, "The Role of the Laboratory in Undergraduate Engineering Education," American Society for Engineering Education Journal of Engineering Education, vol. 94, no. 1, pp. 121-130 (2005)

7. Jennifer Ross and Chu R. Wie, "Utilizing Internet Technologies to Teach Laboratory Courses," Proc. of 25th Annual Conference of the IEEE Industrial Electronics Society, IECON'99, vol. $\quad 1, \quad$ pp. http://ieeexplore.ieee.org/iel5/6620/17776/00822183.pdf.

8. National Instruments, "The NI Electronics Education Platform: A Case Study," http://zone.ni.com/devzone/cda/tut/p/id/3004.

9. Mani Soma and Eve Riskin, "A Hands-on Laboratory-Driven Electrical Engineering 2Year Curriculum for Distance and at-Home Learning," http://www.ee.washington.edu/faculty/soma/fipse/.

10. Ingvar Gustavsson, "A Remote Laboratory for Electrical Experiments," Proceedings of the 2002 American Society for Engineering Education Annual Conference \& Exposition, Session 2359 (2002).

11. J. A. del Alamo, L. Brooks, C. McLean, J. Hardison, G. Mishuris, V. Chang, and L. Hui, "The MIT Microelectronics WebLab: a Web-Enabled Remote Laboratory for Microelectronic Device Characterization," 2002 World Congress on Networked Learning 
in a Global Environment, Berlin, Germany, (2002); http://mtlweb.mit.edu/ alamo/pdf/2002/RC-88\%20delAlamo\%20NL\%202002.pdf

12. US Department of Education Report, "Online Learning Students Perform Better", http://www.breining.edu/USDEDistLearning.htm, May 2009.

13. R. Adams, J. Turns, and C. Atman, "Educating Effective Engineering Designers: The Role of Reflective Practice”, Design Studios 24131, pp. 275-294, (2003).

14. Open SUNY, open.suny.edu 